\title{
Nos labirintos do tempo: a instituição do sujeito nostálgico sob um viés enunciativo
}

\section{In the time mazes: the institution of the nostalgic subject under an enunciative view}

Pós-doutorado em Linguística Aplicada e Estudos da Linguagem - PUC-SP/LAEL (2011); Doutor em (PUCRS/2006); Mestre em Linguística Aplicada pela Universidade do Vale do Rio dos Sinos (UNISINOS/2002). Possui graduação em LETRAS Português/Inglês e respectivas Literaturas, pelo Centro Universitario La Salle (1999). Professor Feevale, Programa de Pós-graduacão em Processos e Manifestaçōes Culturais, e professor permanente no PPG em Letras na Universidade de Passo Fundo (RS). (1) hittps://orcid. org/0000-0002-3290-3955 E-mail: ecesar@upf.br

Mestrando em Letras - Leitura e Formação do Graduado em Letras (UPF-2016). Ĺngua Portuguesa e Língua Inglesa na rede privada de ensino, na cidade de Sarandi/RS. (ii) http://orcid.org/0000-0001-9597-5932 E-mail: rafa1_moura@hotmail.com
Ernani Cesar de Freitas ${ }^{1}$ Rafael da Silva Moura²

RESUMO: Este artigo tematiza o complexo processo de ressignificação textual, constituindo-se um estudo enunciativo de texto do gênero discursivo poema. Objetiva-se, a partir da observação de marcas enunciativo-discursivas inscritas na materialidade textual, analisar a constituição do sujeito nostálgico que se depreende do soneto Nostalgia, da poetiza portuguesa Florbela Espanca, mediante a relação intersubjetiva entre o locutor e o interlocutor. A investigação caracteriza-se como bibliográfica exploratório-descritiva, de natureza aplicada, com abordagem qualitativa, tendo como fio norteador, principalmente, os estudos de Jankélévitch (1974) e Starobinski (2016), acerca da concepção de nostalgia, bem como nos pressupostos conferidos por Benveniste (1976a, 1976b; 2006a, 2006b, 2006c), em relação aos conceitos de língua, linguagem, enunciação e subjetividade. A análise comprova que os recursos linguístico-enunciativos manipulados na materialização discursiva não só corroboram para a construção da subjetividade do enunciador, como, também, interferem na constituição semântica do texto.

Palavras-chave: Nostalgia; Enunciação; Sentidos subjacentes; Poema.

ABSTRACT: This article focus on the complex process of textual resignification, constituting an enunciative study of text of the discursive genre poem. Its objective, from the observation of enunciative-discursive marks inscribed in textual materiality, is to analyze the constitution of the nostalgic subject that appears from the sonnet Nostalgia, of the Portuguese poet Florbela Espanca, through the intersubjective relationship between the announcer and the interlocutor. The research is characterized as an exploratory-descriptive bibliography, of an applied nature, with a qualitative approach, mainly based on the studies of Jankélévitch (1974) and Starobinski (2016), about the conception of nostalgia, as well as in conferred assumptions by Benveniste (1976a, 1976b; 2006a, 2006b, 2006c), in relation to the concepts of language, enunciation and subjectivity. The analysis shows that the linguistic-enunciative resources manipulated in the discursive materialization not only corroborate for the construction of the subjectivity of the enunciator, but they also interfere in the semantic constitution of the text.

Keywords: Nostalgia. Enunciation. Underlying senses. Poem. 


\section{Introdução}

Com vistas a projetar-se e a marcar-se no tempo e no espaço, os sujeitos, historicamente, mobilizam uma variada gama de mecanismos sociodiscursivos e pragmáticos. Evidencia-se, entretanto, que todos os recursos comunicativos utilizados nas atividades interativas associam-se, em alguma medida, ao uso da linguagem. Nessa mesma perspectiva, deve-se considerar que a língua permeia as relações humanas a partir de enunciados concretos, os quais permitem sua materialização/realização. Pode-se dizer, grosso modo, então, que tais enunciados, responsáveis por corporificar e projetar o sistema linguístico em determinada situação comunicativa, são os próprios textos, orais ou escritos, verbais ou verbo-visuais.

A comunicação humana, portanto, efetiva-se por meio de textos, em vista do caráter sociodiscursivo destes, posto que possibilitam aos sujeitos projetarem seus dizeres. Ou seja, as práticas discursivas estão íntima e inerentemente relacionadas à interação estabelecida entre interlocutores, físicos ou virtuais, da atividade linguageira, que perpassa um processo de materialização de concepções abstrato-subjetivas, a partir da apropriação de um sistema linguístico e da corporificação deste em um engendramento textual. Logo, os textos são um produto da necessidade humana de se comunicar com seus semelhantes, bem como de armazenar e difundir conhecimento, vivências e concepções de mundo.

Sob esse viés, configura-se lúcido referir que, visando a compreender o processo interativo instaurado entre os sujeitos por meio da linguagem, bem como a desvelar os sentidos subjacentes a esse processo, seria apropriado o desenvolvimento de um estudo que se debruce sobre o produto final e fomentador da atividade linguageira: o texto. Reconhece-se, entretanto, que o texto literário, por exemplo, confere um trato diferenciado à língua, articulando escolhas enunciativas enriquecidas, o que exige do sujeito-leitor um olhar também diferenciado e mais atento à materialização discursiva, para que seja possível a inferência de sentidos à teia de significações que subjazem a superfície textual.

Diante desse contexto, este artigo tematiza o complexo processo de ressignificação textual, propondo o desenvolvimento de um estudo de natureza interdisciplinar, a partir de aproximações entre pressupostos enunciativos e literários. Ressalta-se, porém, que não se propõe uma fusão entre Enunciação e Literatura, mas, sim, um diálogo articulatório entre seus respectivos pressupostos teórico-metodológicos, enriquecendo, assim, o processo investigativo-analítico. Logo, ao depositar um olhar enunciativo sob um fato literário - um poema -, objetiva-se, neste estudo, a partir do delineamento de um percurso sistemático de leitura, analisar como as marcas enunciativas projetadas no ato enunciativo revelam a constituição do sujeito nostálgico que se depreende do soneto Nostalgia, da poetiza portuguesa Florbela Espanca.

Isso posto, ressalta-se que a investigação aqui inscrita caracterizase como bibliográfica, exploratório-descritiva, de natureza aplicada, com abordagem qualitativa, haja vista que se dedica à análise de marcas enunciativo-discursivas inscritas em um texto de natureza poética, as quais corroboram a construção da subjetividade do enunciador e interferem na constituição semântica do texto, que carrega e manifesta concepções íntimas daquele que enuncia em relação ao universo discursivo do qual participa. Para tanto, buscam-se subsídios basilares ao estudo, principalmente, no seguinte arcabouço teórico: Jankélévitch (1974) e Starobinski (2016), visando à delimitação de concepções teóricas quanto à nostalgia, bem como Benveniste (1976a, 1976b; 2006a, 2006b, 2006c), em relação aos conceitos de língua, linguagem, enunciação e subjetividade, que se constituem categorias semânticas basilares à manifestação discursiva. 
Com vistas a melhor delinear a apresentação do estudo, segue-se o seguinte percurso: na primeira seção, discutem-se os conceitos de língua e linguagem, enunciação e subjetividade, que são edificados na relação entre Homem, Língua e Sociedade; na seção seguinte, são inscritas discussões que visam à delimitação e à semantização do conceito de nostalgia fundamental a este estudo; na terceira seção, após ser apresentado o percurso metodológico adotado, desenvolve-se a análise do poema supracitado, com vistas a fundamentar e balizar uma proposta de leitura a partir de uma interface entre os aspectos teóricos supracitados; e, por fim, na última seção, são apresentadas algumas considerações quanto aos resultados do estudo.

\section{Em foco, aspectos circundantes das relações humanas pela linguagem}

A necessidade de interagir com seus semelhantes é aspecto inerente à natureza humana. Esse processo interativo-comunicativo entre os sujeitos, por sua vez, é viabilizado por diversos recursos pragmático-cognitivos, que, notoriamente, em alguma medida, associam-se ao uso da linguagem. Neste estudo, grosso modo, concebe-se a linguagem enquanto uma habilidade humana de se apropriar de um sistema de signos e organizá-lo de forma a possibilitar a interação com os demais sujeitos que fazem parte de suas relações sociodiscursivas diárias.

Entretanto, "não está provado que a função da linguagem, tal como ela se manifesta quando falamos, seja inteiramente natural, isto é: que nosso aparelho vocal tenha sido feito para falar, assim como nossas pernas para andar" (SAUSSURE, 2006, p.17). Por esse viés, o homem poderia ter utilizado qualquer outro aparelho para criar e manejar um sistema de signos, tal como construir imagens sensoriais por meio de gestos, a fim de proporcionar a interação, mas, talvez, por razões de facilidade ou de amplitude de modulação, serve-se do aparelho vocal como instrumento da língua.

Ou seja, não é a linguagem um elemento "natural ao homem, mas a faculdade de construir uma língua, vale dizer: um sistema de signos distintos correspondentes a ideias distintas" (SAUSSURE, 2006, p. 18). Esse sistema de signos manifesta uma atividade simbólica, um conjunto de combinações utilizadas por determinado grupo social que permite a criação de conceitos que sirvam para categorizar, organizar e interpretar a realidade do mundo.

Nas palavras de Saussure (2006), a língua representa a parte social e psíquica da linguagem, cuja essência é independente das vontades do indivíduo, que a "registra passivamente", enquanto produto de um conjunto de convenções e relações sociodiscursivas necessárias. Ou seja, de acordo com o mestre genebrino, a língua se constitui em um

tesouro depositado pela prática da fala por todos os indivíduos pertencentes à mesma comunidade, um sistema gramatical que existe virtualmente em cada cérebro ou, mais exatamente, nos cérebros dum conjunto de indivíduos, pois a língua não está completa em nenhum, e só na massa ela existe de modo completo (SAUSSURE, 2006, p. 45).

Reconhecendo a natureza abstrata, embora crucial, desse dispositivo comunicativo responsável pelas relações sociodiscursivas entre parceiros de determinada atividade comunicativa, Benveniste (1976a, 1976b; 2006a, 2006b, 2006c), por sua vez, a partir dos pressupostos delineados pelo mestre genebrino, debruça-se sobre o fenômeno linguístico considerando a língua em funcionamento. A atenção desse estudioso se volta, principalmente, à posição do homem enquanto sujeito que se apropria de um sistema de signos, neste caso, a língua, para estabelecer uma relação comunicativointerativa com seus semelhantes, e aos fenômenos relacionados a esse processo. Instaura-se, por conseguinte, a concepção de enunciação, que 
é concebida como "este colocar em funcionamento a língua por um ato individual de utilização". A enunciação, portanto, não deve ser confundida com o produto final desse processo - o texto -, posto que "é o ato mesmo de produzir um enunciado, e não o texto do enunciado, que é o nosso objeto. Este ato é o fato do locutor que mobiliza a língua por sua conta" (BENVENISTE, 2006a, p. 82).

A língua, então, confere ao sujeito a capacidade de nomear o mundo e de exteriorizar um universo interior e subjetivo, por isso "não atingimos nunca o homem separado da linguagem e não o vemos nunca inventando-a" (BENVENISTE, 1976a, p. 285). Mas, antes de ser acionada pelos usuários, ela nada mais é do que uma possibilidade, um sistema abstrato à disposição dos falantes. Ou seja, apenas "depois da enunciação, a língua é efetuada em uma instância de discurso" (BENVENISTE, 2006a, p. 83).

Apesar de a língua configurar-se nesse elo entre o homem e o mundo, Benveniste (1976a, 2006c) refuta a ideia de considerá-la um mero instrumento dos sujeitos em suas relações comunicativo-interativas diárias. Pelo contrário: embora seja algo criado e estabelecido por uma convenção social, a língua é interna ao ser humano, portanto psíquica e fisiológica, e não pode ser comparada a um instrumento, que seria externo e material. Ainda, reforçando o caráter primordial da língua, Benveniste (2006c, p. 63) ressalta que é apenas ela que "torna possível a sociedade", uma vez que "constitui o que mantém juntos os homens, o fundamento de todas as relações que por seu turno fundamentam a sociedade".

Mesmo sendo uma ação individual do sujeito, a enunciação é calcada na relação discursiva que este exerce com um parceiro, real ou idealizado, ou seja, não haveria motivo para se enunciar, para se manifestar linguisticamente, sem ter o objetivo de interagir com um outro, com vistas a produzir uma ação, uma resposta, uma adesão, um posicionamento etc. Logo, "não atingimos jamais o homem reduzido a si mesmo e procurando conceber a existência do outro. É um homem falando que encontramos no mundo, um homem falando com outro homem" (BENVENISTE, 1976a, p. 285).

Nesse processo dialógico, então, o sujeito apropria-se do aparelho formal da língua, e das possibilidades semânticas por ele proporcionadas, e enuncia-se, projetando o seu dizer na instância discursiva. Tem-se, por conseguinte, uma situação enunciativa, em que aquele que toma a palavra é designado por "eu", direcionando seu discurso, explicita ou implicitamente, a um "tu", seu interlocutor. Há, entretanto, uma propriedade de reversibilidade entre esses sujeitos do discurso, em que, quando o "tu" toma para si o curso da palavra, ele acaba por configura-se em um "eu", e o "eu" anterior passa a ser o "tu". Essas duas categorias de pessoa - "eu" e "tu" - manifestam uma oposição semântico-discursiva a um "ele", considerado a não pessoa do discurso, por ser apenas o objeto do dizer ou todo aquele que não participa do circuito de troca dialogal, que não se manifesta neste (BENVENISTE, 1976a, 2006c).

Nessa dinâmica interativa de personalidade, estabelecesse-se a subjetividade e a correlação desta com os sujeitos, uma vez que o poder de discursivização da língua pertence unicamente ao "eu", que seria, portanto, a pessoa subjetiva, enquanto "tu" configura-se a pessoa não subjetiva ("ele" permanece sendo a não-pessoa). Benveniste (1976a, p.286) afirma que "a consciência de si só é possível se experimentada por contraste" e que "a linguagem só é possível porque cada locutor se apresenta como sujeito, remetendo a ele mesmo como eu do discurso". Sem enunciar-se, o homem deixa de participar ativamente de atividades sociais pela linguagem, pois, não corporificando seu discurso, passa a assumir a posição da não pessoa do discurso, aquela que é um objeto no universo discursivo. Logo, "é na linguagem e pela linguagem que o homem se constitui sujeito" (BENVENISTE, 1976a, p. 286). 
A subjetividade, nas palavras de Benveniste (1976a, p.286), é capacidade do locutor se apropriar do sistema linguístico e propor-se como sujeito de seu dizer: um sujeito discursivo, que se projeta no discurso e nele deixa marcas de pessoalidade, da inscrição do "eu". O enunciador manifesta seu "ego", dizendo "eu", com vistas a atingir um "eco", que seria o "tu". Além dos pronomes revelados na primeira pessoa na materialidade discursiva, outro aspecto que marca a subjetividade na linguagem são os indicadores da deixis: "demonstrativos, advérbios, adjetivos, que organizam as relações espaciais e temporais em torno do 'sujeito' tomado como ponto de referência: 'isto, aqui, agora' e as suas numerosas correlações 'isso, ontem, no ano passado, amanhã', etc." (BENVENISTE, 1976a, p. 288).

O sujeito, assim sendo, marca-se na linguagem por meio da subjetividade ao instaurar-se no discurso por um "eu", inserido no espaço do "aqui" e no tempo do "agora", que são reconhecidos pelo alocutário ao entrar em contato com o enunciado. E esse projeto enunciativo desenvolvido pelo sujeito visa a reproduzir a realidade de acordo com seu olhar individual e projetá-la ao seu interlocutor, por meio da linguagem. Assim, "aquele que fala faz renascer pelo seu discurso o acontecimento e a sua experiência do acontecimento. Aquele que o ouve apreende primeiro o discurso e através desse discurso, o acontecimento reproduzido" (BENVENISTE, 1976b, p. 26).

Ressalta-se, por fim, o "poder fundador da palavra, que instaura uma realidade imaginária, anima as coisas inerentes, faz ver o que ainda não existe, traz de volta o que desapareceu" (BENVENISTE, 1976b, p.27), construindo (ou reconstruindo), assim, realidades e concepções de mundo, bem como projeções de sentimentos e conceitos internos ao ser humano, como o de nostalgia, categoria semântica sobre o qual se discorre na seção seguinte.

\section{A (im)possibilidade de retorno: desvelando a concepção de nostalgia}

São diversas as áreas do conhecimento que colocam em pauta o fato de ser intrínseco à natureza humana, no processo de constituição de uma identidade social, recorrer a feitos e a vivências inscritos em um tempo passado, a fim de, a partir de uma espécie de atividade comparativoconstitutiva, instituir uma imagem e um espaço sócio-histórico-discursivos propriamente contemporâneos. Esse elo semântico entre presente e passado, inevitavelmente - embora em níveis de profundidade distintos -, fomenta a projeção de um sentimento nostálgico nos sujeitos inseridos no referido processo identitário. Percebe-se, assim, que a nostalgia configurase, em certa medida, elemento inerente às atividades sociodiscursivas, o que justifica a conferência de um olhar mais sistemático e teórico-semantizador sobre esse conceito.

Diante disso, deve-se ponderar que a diversidade das áreas do saber que se dedicam ao estudo da nostalgia refletem na projeção de concepções a ela referidas também diversas, dependendo do viés teórico-metodológico assumido, bem como do recorte temporal no qual o estudo se insere. Logo, ressalta-se que, visando a melhor delinear a posição discursiva assumida, neste estudo, em relação ao referido conceito - de natureza tão abstrata -, dedica-se este espaço para traçar breves considerações e retomadas teóricas na tentativa de fundamentar uma construção conceitual.

Recorre-se, então, como ponto de partida, aos postulados de Starobinski (2016, s.p.), que, iniciando o processo de definição da categoria semântica "nostalgia", assevera que se pode considerá-la um "transtorno íntimo ligado a um fenômeno de memória", a qual diz respeito a uma atividade discursiva que possibilita a conservação, a organização e a difusão de saberes, valores, vivências e conceitos socioculturais. De acordo com o autor, nos primeiros 
estudos desenvolvidos sobre nostalgia, em 1688, cujo precursor foi o médico suíço Johannes Hofer, ela fora concebida como uma doença. Ou seja, o vocábulo "nostalgia" designava a "dor do retorno" - mais especificamente, a dor do não-retorno à pátria.

A referida concepção delineou-se em um espaço geográfico e temporal cujas relações sociodiscursivas se constituíram em torno de exílios e de distintas formas de distanciamentos da terra natal, na maioria das vezes, de maneira forçosa. Esse afastamento involuntário inscreve nos sujeitos marcas de naturezas diversas, dependendo, obviamente, das condições que o levaram a acontecer, assim como das vivências póstumas ao acontecimento. Logo, para se entender a motivação do sentimento nostálgico e as memórias por ele propagadas

é preciso examinar as condições em que um homem se afastava de seu lugar natal. Uma coisa é partir munido de dinheiro, tendo livremente escolhido o itinerário e a duração de sua ausência, outra coisa é se afastar obrigado a isso, para viver uma vida dependente e monótona (STAROBINSKI, 2016, s.p.).

Nessa mesma perspectiva, Starobinski (2016, s.p.) ressalta que "no fim do século XVIII, começam-se a temer os longos afastamentos do próprio país, porque se fica sabendo que a nostalgia ameaça, e chega-se a morrer [por causa dela]". Além disso, o estudioso ressalta que a literatura da época registra e declara que esse conceito diz respeito a uma doença mortal, que, fomentada por uma memória seletiva e, talvez, enganosa, faz com que o sujeito perca o prazer de viver o aqui e o agora.

A nostalgia, desse modo, seria uma "doença" promovida por uma irrefreável atração por tempos e espaços circunscritos em um passado vivido e/ou imaginado, podendo ser associada a estados de espírito depressivos, edificados sobre o sentimento de perda, de luto não completo. Essa abordagem permite que se considere a nostalgia relacionada ao desejo de fuga de um presente desconfortável, que projeta o imaginário do sujeito que se considera oprimido a um tempo que o consola, embora se reconheça a impossibilidade de alcançá-lo ou de revivê-lo.

Essa concepção voltada, mais especificamente, ao distanciamento e a impossibilidade de retorno à terra natal recebe um novo tratamento semantizador quando, em 1880, Philippe Pinel, um respeitado médico francês, propõe que se conceba a nostalgia fundamentada ao diagnóstico de ares de tristeza, melancolia, apatia e indiferença por tudo. Nesse sentido, evidencia-se que a nostalgia

não mais designa [unicamente] uma pátria perdida, mas remonta a estágios em que o desejo não precisa levar em conta o obstáculo externo e não estava condenado a diferir a sua realização. Para o homem civilizado que não tem mais enraizamento, o que cria problema é o conflito entre as exigências da integração ao mundo adulto e a tentação de conservar os privilégios da situação infantil. (STAROBINSKI, 2016, s.p.).

Sob uma perspectiva mais contemporânea, ao debruçar-se sobre a temática fundadora desta seção, Jankélévitch (1974) propõe uma nova abordagem conceitual à nostalgia, afastando-a da noção de doença e, consecutivamente, sugere que se adote a noção de sentimento. De acordo com o referido autor, essa categoria semântica deve ser entendida como uma algia (dor), motivada e determinada, mesmo que subconscientemente, configurando-se um mal instituído em uma origem, uma fonte temporal que se busca reencontrar, mesmo que virtualmente. Em outras palavras, pode-se compreender a nostalgia como

uma melancolia humana possibilitada pela consciência, que é a consciência de outra coisa, a consciência de um outro lugar, a consciência de um contraste entre o passado e o presente, entre o presente e o futuro. [...] A nostalgia é simultaneamente aqui e ali, nem aqui nem lá, presente e ausente (JANKÉLÉVITCH, 1974, p. 126, tradução livre). 
Parece lúcido referir, nesse viés reflexivo, que a nostalgia configura-se em um tipo de memória - coletiva ou individual -, enquanto uma atividade de reminiscência e de imaginação, que, devido sua potencialidade de evocação temporal e espacial de um já posto e finalizado, (re)constrói espaços sociodiscursivos frutos de um imaginário - que também se inscreve entre o individual e o coletivo. Observa-se, portanto, a projeção de um sujeito fisicamente presente em um "aqui", mas que se sente ausente de espírito do espaço em que está presente na carne.

A memória, nesse viés, cumpre ressaltar, não significa retorno ou reprodução do que foi, mas, sim, uma atividade discursivo-constitutiva que evoca experiências distintas, mas que se unem por meio de uma percepção afetiva, que, consecutivamente, projeta perspectivas temporais, de certa fora, contaminadas pela ilusão de um passado virtual e idealizado, em que vivências simplórias e, até mesmo ordinárias, observadas por meio de um filtro afetivo, recebem extrema valoração semântica quando confrontado com um presente penoso ou com um futuro incerto.

Considerando, então, que as memórias projetadas do passado influenciam, mesmo que indiretamente, as sensações e impressões sociais do momento em que se vive, podendo orientar as ações humanas, observase um esmagamento do presente. Ou seja, a racionalização da existência humana e social, embora se manifesta em um eterno "agora", aponta para uma experiência de rememoração, de reviver um passado intangível, que é (re)atualizado nos discursos e, imbricadamente, nas relações interativas contemporâneas, potencializando-se em uma expectativa do porvir, do futuro também idealizado, em que vivências passadas se revelam passíveis de serem retomadas e reexperimentadas.

Jankélévitch (1974, p.128, tradução livre), nesse mesmo sentido, ressalta que a nostalgia, baseada em uma disjunção temporal e espacial, manifesta sua natureza fundamentada na irreversibilidade do tempo que "é a explicação mais profunda desta profundidade: porque é a temporalidade irreversível que está subjacente à separação irreparável e rasgadora do criador e da criatura. [...] O irreversível é, portanto, o pensamento que está por trás de cada pensamento [nostálgico]". Logo, a impossibilidade de retorno institui uma arena discursivo-social, em que o nostálgico constrói uma encenação cognitiva e espectral de uma segunda vida, de uma vida poética e sonhadora que se realiza nas margens da vida cotidiana, como uma forma de renegação, de crítica ou descontentamento com contemporâneo.

Isso posto, observa-se, enfim, em conformidade com Starobinski (2016, s.p.) e Jankélévitch (1974), que a literatura, sendo por natureza a arte da palavra, tem a capacidade de não somente armazenar memórias, como um arquivo sociohistórico, mas, também, como um veículo discursivo, fomentar e nutrir a imaginação, a construção de mitos e a experiência virtual de sentimentos, como o da nostalgia. Assim sendo, com vistas a desvelar o processo discursivo que possibilita a inscrição e a encenação de um sentimento nostálgico em textos de caráter literário, dedica-se a seção seguinte à construção de um aparato teóricometodológico que fundamente a proposta de leitura enunciativa aqui apresentada.

\section{Em questão, a procura de sentidos: desenhando um percurso metodológico}

Nesta seção, com base nos preceitos teóricos abordados anteriormente, desenvolve-se um estudo enunciativo do soneto Nostalgia, da poetiza portuguesa Florbela Espanca, veiculado nas mídias digitais, visando a elucidar como as marcas enunciativas projetadas na materialidade discursiva revelam a constituição do sujeito nostálgico que se depreende 
do referido texto. Ressalta-se, nesse sentido, que embora Benveniste (1976a, 1976b; 2006a, 2006b, 2006c) não apresente, explicitamente, uma metodologia de análise, o próprio autor indica um percurso de leitura enunciativa, ao referir que "na enunciação, consideraremos, sucessivamente, o próprio ato, as situações em que ele se realiza e os instrumentos de sua realização" (Benveniste, 2006a, p. 83). Logo, apesar de as propriedades semânticas dos textos se inscreverem, impreterivelmente, na unidade projetada em sua globalidade discursiva, reconhece-se que, no processo analítico, é possível isolar alguns aspectos semânticos e pragmáticos, em um procedimento didático, a fim de depositar um olhar sistemático ao objeto de estudo.

Ao considerar, porém, a complexidade do objetivo norteador deste estudo, que remete a um conceito semântico abstrato e subjetivo, a nostalgia, evidencia-se a necessidade de buscar suporte, também, em preceitos da Literatura (JANKÉLÉVITCH,1974; STAROBINSKI, 2016), com o propósito de elucidar, de maneira mais concisa e fundamentada, sob que viés se assume a referida categoria semântica, a qual se constitui fio ligamentar de todo o processo de leitura/análise.

Ante as considerações supracitadas, para melhor observação do percurso de leitura proposto, expõe-se, a seguir, um quadro sinóptico, o qual se concebe, aqui, como dispositivo de análise e interpretação textual:
Quadro 1. Dispositivo de análise

\begin{tabular}{|c|c|c|c|}
\hline $\begin{array}{l}\text { Estágios } \\
\text { de análise }\end{array}$ & $\begin{array}{c}19 \\
\text { Oato } \\
\text { enunciativo }\end{array}$ & $\begin{array}{c}2^{o} \\
\text { A situação } \\
\text { de comunicação }\end{array}$ & $\begin{array}{l}3^{o} \\
\text { Os instrumentos } \\
\text { enunciativos }\end{array}$ \\
\hline $\begin{array}{l}\text { Objeto } \\
\text { de análise }\end{array}$ & $\begin{array}{c}\text { Marcas enunciativas que } \\
\text { evidenciam a presença } \\
\text { de um locutor (eu), que } \\
\text { se apropria do sistema } \\
\text { linguístico a fim de } \\
\text { estabelecer uma relação } \\
\text { comunicativo-interativa } \\
\text { intersubjetiva com } \\
\text { um interlocutor (tu), } \\
\text { constituindo-se, assim, } \\
\text { como sujeito. }\end{array}$ & $\begin{array}{l}\text { Marcas enunciativas da } \\
\text { deixis, que inscrevem } \\
\text { o discurso em um } \\
\text { "aqui" e um "agora", } \\
\text { respectivamente espaço } \\
\text { e tempo sociodiscursivos } \\
\text { que circunscrevem a } \\
\text { atividade comunicativo- } \\
\text { interativa. }\end{array}$ & $\begin{array}{l}\text { Os recursos linguísticos } \\
\text { mobilizados na } \\
\text { manifestação } \\
\text { discursiva: vocabulário, } \\
\text { arranjos semânticos } \\
\text { e sintagmáticos, por } \\
\text { exemplo, com atenção } \\
\text { especial aos efeitos de } \\
\text { sentido provocados. }\end{array}$ \\
\hline $\begin{array}{l}\text { Categoria } \\
\text { semântica } \\
\text { balizadora }\end{array}$ & \multicolumn{3}{|c|}{$\begin{array}{l}\text { A categoria semantizadora que norteia e unifica o estudo, ou seja, } \\
\text { um conceito/um signo linguístico (neste caso, "Nostalgia”) sobre o qual os esforços analíticos } \\
\text { se debruçam à procura de sentidos, perpassando todos os estágios de análise. }\end{array}$} \\
\hline $\begin{array}{l}\text { Projeção } \\
\text { semântica } \\
\text { resultante }\end{array}$ & \multicolumn{3}{|c|}{$\begin{array}{l}0 \text { sentido global do texto, subjacente à sua superfície textual, depreendido com base na } \\
\text { leitura dos aspectos enunciativo-discursivos inscritos na materialidade discursiva. }\end{array}$} \\
\hline
\end{tabular}

Fonte: Os autores.

Os pressupostos teórico-metodológicos explorados (BENVENISTE, 1976a, 1976b; 2006a, 2006b, 2006c; JANKÉLÉVITCH, 1974; STAROBINSKI, 2016), que foram sistematizados e articulados em forma de dispositivo de análise, configuram-se como uma base sólida, coerente e produtiva para aplicação na leitura de materialidades linguísticas de natureza literária, como se observa na próxima seção. 


\section{1 “Quero voltar!": os vestígios enunciativos e a projeção do sujeito nostálgico}

Seguindo, então, o percurso metodológico delineado anteriormente, passa-se à análise do referido corpus, cuja transcrição apresenta-se a seguir.

\section{Nostalgia $^{1}$}

Nesse País de lenda, que me encanta,

Ficaram meus brocados, que despi,

$\mathrm{E}$ as joias que pelas aias reparti

Como outras rosas de Rainha Santa!

Tanta opala que eu tinha! Tanta, tanta!

Foi por lá que as semeei e que as perdi..

Mostrem-me esse País onde eu nasci!

Mostrem-me o Reino de que eu sou Infanta!

0 meu País de sonho e de ansiedade,

Não sei se esta quimera que me assombra,

É feita de mentira ou de verdade!

Quero voltar! Não sei por onde vim...

Ah! Não ser mais que a sombra duma sombra

Por entre tanta sombra igual a mim!

Como ponto de partida, enfatiza-se que, a cada situação comunicativa, prospectando o desenvolvimento de um projeto enunciativo que tanto torne seu discurso inteligível, como também cumpra uma finalidade discursiva, o sujeito mobiliza a língua de maneira específica, adequando-a à intenção de comunicação, por intermédio de escolhas que criam uma série de efeitos formais e funcionais que, consequentemente, refletem-se na constituição textual.

${ }^{1}$ O referido corpus, devido à facilidade e praticidade de acesso, fora transcrito do meio digital. Para
conferência, verificar o seguinte endereço eletrônico: www.citador.pt/poemas/nostalgia-florbela-deconferencia, verificar o s à
Nesse mesmo sentido, Benveniste (2006a, p.86) assevera que "desde o momento em que o enunciador se serve da língua para influenciar de algum modo o comportamento do alocutário, ele dispõe para este fim de um aparelho de funções", que lhe permite articular o sistema linguístico de maneiras distintas, com vistas a criar determinados efeitos de sentido. A constituição textual, portanto, deve-se à intenção discursiva de um locutor, que manifesta em seu dizer marcas e instruções de leitura, a fim de que o interlocutor realize operações cognitivas destinadas a nortear a compreensão do texto em sua integralidade semântica, para, consecutivamente, (re)agir diante dos sentidos projetados por esse dispositivo discursivo.

Considerando, então, que as marcas linguístico-enunciativas projetadas pelo enunciador na materialidade textual possibilitam inferir os sentidos inscritos em sua subjacência discursiva, inicia-se o processo de leitura do referido poema a partir do primeiro estágio de análise, o ato enunciativo, com vistas a desvelar a relação intersubjetiva estabelecida entre o locutor, o interlocutor e o universo discursivo que circunda essa interação. No que diz respeito a esse aspecto, Benveniste (1976a, 1976b; 2006a, 2006b, 2006c) convoca os estudos linguísticos a conferirem fundamental atenção à posição do homem enquanto sujeito que se apropria de um sistema de signos, para estabelecer uma relação comunicativo-interativa com seus semelhantes, e aos fenômenos enunciativo-discursivos relacionados a esse processo. Nesse sentido, configura-se apropriado ressaltar que textos de natureza poética, como é o caso do soneto em análise, têm por objeto um "eu", que manifesta uma concepção de mundo por meio de um olhar único, partindo de reflexões subjetivas do enunciador/autor. Seguindo, consecutivamente, as proposições benvenistianas, reconhece-se que "o ato individual de apropriação da língua introduz aquele que fala em sua fala", e isso, assim como na poesia, "é um dado constitutivo da enunciação" (BENVENISTE, 2006a, p. 84). 
Baseando-se nessas concepções, é possível observar algumas marcas que evidenciam a inserção do enunciador no discurso projetado no soneto Nostalgia, a saber: a) os pronomes objetos "me" - inscrito no primeiro, sétimo, oitavo e décimo versos - e "mim" - no décimo quarto verso -, assim como os pronomes possessivos "meus" e "meu" - inseridos, respectivamente, no segundo e no nono verso; b) o próprio pronome da primeira pessoa do singular, "eu" - no quinto, sexto e oitavo versos - , bem como verbos relacionados a essa pessoa do discurso - "despi", "reparti”, "tinha”, "semeei", "perdi", "nasci”, “sou”, "não sei”, "quero", "vim”. A inscrição desses vocábulos que circunscrevem índices específicos relacionados à primeira pessoa deixa transparecer a presença do enunciador enquanto sujeito de seu dizer, revelando algumas "formas específicas cuja função é de colocar o locutor em relação constante e necessária com a enunciação" (BENVENISTE, 2006a, p. 84). Apresentando marcas de pessoalidade, portanto, o enunciado revela também traços de subjetividade.

Observa-se, assim, que o poema se articula com vistas a exprimir o sentimento do enunciador (a dor, a insatisfação, a tristeza, a nostalgia) frente a uma ação externa involuntária aos seus desejos, e talvez, a partir disso, conduzir o leitor/enunciatário a refletir um pouco mais sobre si mesmo e sua relação com o mundo. O "eu" lírico, ou o "eu" enunciativo, assim sendo, apropria-se virtualmente da língua e manifesta o seu discurso no mundo por meio de um engendramento discursivo subjetivo. Assim, ao declarar-se sujeito, o locutor "implanta o outro diante de si, qualquer que seja o grau de presença que ele atribua a este outro", posto que, "toda enunciação é, explicita ou implicitamente, uma alocução" e, para tanto, "ela postula um alocutário" (BENVENISTE, 2006a, p. 84). Instaura-se, então, uma relação propriamente enunciativa, em que um "eu" se dirige a um "tu".

Considerando que, no poema analisado, o "eu" enunciativo é revelado pelo "eu" lírico, que corporifica um sujeito-discursivo virtualizado e, de certa forma, generalizado - uma vez que, ao não ser nomeado, representa todos os seres e, ao mesmo tempo, nenhum em específico -, reconhece-se, consecutivamente, a viabilidade de se depreenderem três possíveis "tu" desse processo enunciativo:

a) o primeiro seria o próprio "eu" lírico, que se manifesta em forma de monólogo, recurso este que, na concepção postulada por Benveniste (2006a, p.87), seria um "diálogo interiorizado, formulado em 'linguagem interior', entre um eu locutor e um eu ouvinte [...]". Assim sendo, apenas o "eu" locutor se manifesta discursivamente - o "eu ouvinte permanece, entretanto, presente; sua presença é necessária e suficiente para tornar significante a enunciação do eu locutor" (BENVENISTE , 2006a, p. 87). Nesse viés, podese afirmar que, em certa medida, o "eu" lírico inscrito no soneto Nostalgia estaria à procura da própria imagem, constituída e articulada na superfície de um mundo físico-espectral, manifestando, assim, um discurso reflexivo sobre a própria existência, dirigindo-se, portanto, a si mesmo.

b) quanto ao segundo "tu", cumpre ressaltar que, embora o poema, em sua totalidade, seja engendrado em forma de monólogo, é possível observar, no sétimo e oitavo versos, a relação explícita do "eu" lírico/enunciativo com um interlocutor. Ou seja, a expressão "Mostrem-me", inscrita nos versos supracitados, ao projetar a forma imperativa pluralizada do verbo "mostrar" ("mostrem"), desvela que o enunciador dirige-se diretamente a alguém. Assim, por meio do referido modo verbal, que inscreve ordens, apelos e/ou aconselhamentos, aquele que enuncia visa a provocar no interlocutor certo comportamento, que, conforme se observa mais detalhadamente a seguir, diz respeito a uma ação colaborativa, com vistas a conduzir o enunciador no processo de retomada de seu espaço geográfico natal perdido.

c) a terceira possibilidade de "tu" seria o leitor, que é quem opera sobre o texto, mobilizando seus conhecimentos enciclopédicos e linguísticos, a fim de inferir os sentidos subjacentes à materialidade discursiva. A perspectiva 
de reversibilidade e de continuidade de um diálogo, mesmo que virtual, projetada neste último caso, manifesta-se na possibilidade de agenciamento do leitor diante do discurso que emana do texto, o que estabelece uma relação intersubjetiva entre um "eu"/autor/enunciador e um "tu"/leitor/ enunciatário.

Além disso, observa-se, nesse poema, a presença do terceiro elemento do quadro discursivo proposto por Benveniste (1976a, 2006a): a nãopessoa. Dentre várias acepções conferidas a essa categoria enunciativa, assume-se, aqui, que todo o conteúdo temático abordado na relação comunicativo-interativa pode, de certo modo, configurar-se um "ele". Logo, o objeto do dizer, que, na atividade discursiva manifestada no soneto Nostalgia, fundamenta a relação intersubjetiva estabelecida entre o "eu" lírico/enunciativo e o "tu", seriam os elementos sobre os quais a interação se articula, a saber: o país de origem do enunciador, os bens deixados para trás, bem como as riquezas e glórias de um tempo passado. Esse engendramento discursivo, observado na constituição do ato enunciativo do referido soneto, já revela traços do sentimento nostálgico nele projetado, uma vez que a nostalgia pode ser caracterizada como um "estar", "[...] ao mesmo tempo aqui e lá, nem aqui nem lá, presente e ausente" (JANKÉLÉVITCH, 1974, p. 126, tradução livre).

Quanto a isso, Starobinski (2016) ressalta a necessidade de se distinguir a noção de nostalgia sob dois vieses: a) relacionada a um espaço físico que se perdeu e que se deseja ter de volta; b) ou relacionada à noção de desajustamento, que leva o sujeito a prever o progressivo declínio do presente, em relação ao passado. Essa distinção é possibilitada ao dedicarse à análise da situação da enunciação, - aspecto sobre o qual se debruça a seguir, e diz respeito ao segundo estágio do percurso analítico proposto neste estudo -, que circunscreve um tempo e um espaço discursivamente determinados.
Nesse sentido, os postulados benvenistianos (1976a) indicam que a enunciação - portanto, a interação discursiva - manifesta-se ancorada a diversos indicadores da deixis, cuja constituição se fundamenta em uma variada gama de elementos semântico-pragmáticos "que organizam as relações espaciais e temporais em torno do 'sujeito' tomado como ponto de referência: 'isto, aqui, agora' e as suas numerosas correlações 'isso, ontem, no ano passado, amanhã', etc.” (BENVENISTE, 1976a, p. 288). Ou seja, o sujeito, ao corporificar seu projeto enunciativo, com vistas a reproduzir a realidade de acordo com seu olhar individual e projetá-la ao seu interlocutor, insere seu discurso no espaço do "aqui" e no tempo do "agora".

Quanto ao espaço enunciativo projetado na materialidade do poema, é possível observar a inscrição de alguns pronomes demonstrativos, de advérbios e substantivos que organizam o desenvolvimento do projeto enunciativo delineado pelo enunciador, uma vez que tornam viável a construção de um espaço, que, na perspectiva benvenistiana (1976a), não diz respeito a um ambiente físico, mas, sim, ao ambiente discursivo interno e externo à enunciação. Nesse sentido, já no primeiro verso do soneto "Nesse país de lenda, que me encanta" -, o pronome "nesse", cuja natureza semântico-gramatical inscreve certo distanciamento físico entre aquele que enuncia e o objeto por ele referido, revela uma condição de afastamento do "eu" lírico em relação ao país mencionado - que é seu objeto de desejo.

Também, observa-se a inscrição do advérbio "lá", no sexto verso, enfatizando um paralelo entre o momento da enunciação, que ocorre em um "aqui", e o ambiente almejado pelo enunciador - o "país de lenda", o "país de sonho", o "reino" natal -, reforçando, assim, a ideia de disjunção física entre o "eu" lírico e o espaço que lhe inquieta a memória. Tal inquietação e insatisfação com o espaço em que se está inserido, reforçada pelo desejo de retorno - corroborado pelo décimo segundo verso, "Quero voltar!" -, é característica própria de um sujeito nostálgico, que, conforme Jankélévitch 
(1974, p. 173, tradução livre), "roca-se na invencível esperança [de retorno], porque se reconhece cidadão de uma outra cidade e de um outro mundo, porque a sua pátria é uma cidade invisível situada no infinito".

Quanto ao tempo da enunciação, recorre-se às palavras de Benveniste (2006b, p.71, grifo do autor), com vistas a esclarecer que "denominamos 'tempo' a continuidade em que se dispõem em série estes blocos distintos que são os acontecimentos". Há, entretanto, uma tênue distinção entre tempo cronológico e tempo linguístico. Este último, objeto da enunciação, relaciona-se ao exercício da linguagem e organiza-se na materialização discursiva, centrando-se na instância presente da atividade linguística, que é delineada sempre em um "agora". Assim, o tempo presente configura-se a principal referência semântica para as oposições temporais possibilitadas pela língua, uma vez que fundamenta

a linha de separação entre dois outros momentos engendrados por ele e que são igualmente inerentes ao exercício da fala: o momento em que o acontecimento não é mais contemporâneo do discurso, deixa de ser presente e deve ser evocado pela memória, e o momento em que o acontecimento ainda não é presente, virá a sê-lo, e se manifesta em prospecção (BENVENISTE, 2006b, p. 75).

Todas as línguas, assim como as relações discursivas por elas possibilitadas, organizam-se semanticamente em razão do tempo, que pode ser marcado pela maneira como são conjugados os verbos ou, até mesmo, por determinadas palavras. 0 primeiro e o décimo versos do poema em análise, por exemplo, inscrevem os verbos "encantar", "saber" e "assombrar" em suas formas do presente do indicativo ("Nesse País de lenda, que me encanta"; "Não sei se esta quimera que me assombra"), ressaltando que o encantamento, o desconhecimento e a assombração sentidos e descritos pelo "eu" lírico/enunciativo são contemporâneos e simultâneos ao momento da enunciação. Os demais versos da primeira estrofe, bem como os dois primeiros da segunda, por sua vez, apresentam formas verbais referentes ao pretérito do indicativo - ficaram, despi, reparti, tinha, semeei, perdi -, desvelando, assim, a transposição do olhar do enunciador para um tempo inscrito no passado, portanto, finalizado.

Esse elo semântico discursivamente estabelecido entre aquilo que está posto e o que está em andamento, conforme Jankélévitch (1974, p.126, tradução livre), é outra forma de sustentação da inquietação do nostálgico, que edifica sua existência na "consciência de um alhures, consciência de um contraste entre passado e presente, entre presente e futuro". O que torna essa perspectiva de vida problemática não é o desejo pelo que não existe, mas, sim, o desejo de reviver, de voltar ao que já não existe mais, ao que faz parte de um tempo finalizado.

A referida aspiração de retorno fica ainda mais evidente no sétimo, oitavo e décimo segundo versos, transcritos, respectivamente, a seguir: "Mostrem-me esse País onde eu nasci!", "Mostrem-me o Reino de que eu sou Infanta!", “Quero voltar! Não sei por onde vim...”. Nesses versos, a inscrição do verbo "mostrar" na forma imperativa possibilita a construção do efeito de sentido de apelo, que também é simultâneo ao momento da atividade linguística, em que o enunciador projeta seu dizer em um espaço discursivo. Essa mesma consonância entre a projeção temporal manifestada pela conjugação verbal e a atividade enunciativa se repete com os verbos "querer" e "saber", que são apresentados em suas formas no presente do indicativo.

Observa-se, ainda nos versos supracitados, que os verbos "nascer" e "ser", devido a suas conjugações em tempos verbais distintos, fundamentam uma estreita relação semântica entre passado e presente, posto que, por ter nascido no referido país - que não é nomeado -, o "eu" lírico carrega laços afetivos que se mantêm latentes no momento da manifestação linguística por ele articulada, reforçando, assim, o sentimento de pertencimento como 
contemporâneo ao processo discursivo-enunciativo. O décimo terceiro verso - "Não ser mais que a sombra duma sombra" -, por sua vez, ao projetar o verbo "ser" em sua forma infinitiva, insere uma nova perspectiva temporal no poema, pois direciona o discurso nele inscrito a um tempo futuro, em que, pode-se inferir, seria possível reviver, de forma atualizada, experiências passadas.

Evidencia-se, então, que o "eu" lírico/enunciativo manifesta explicitamente seu anseio por retornar à terra natal, mas que, por motivos não elucidados no poema, sua memória lhe nega o conhecimento do caminho que o trouxe ao espaço em que está inserido e, consecutivamente, poderia levá-lo de volta ao local de sua origem. Quanto a isso, cumpre ressaltar que o tempo desloca-se sem fim e sem possibilidade de retorno, ou seja, "não reencontramos jamais nossa infância, nem o ontem, nem o instante que acaba de passar" (BENVENISTE, 2006b, 71). Logo, embora seja possível ir e voltar no espaço físico - mesmo que não se encontre o lugar natal da mesma forma conservada pela memória -, a irreversibilidade do tempo impede que a falta exaltada pela nostalgia seja minimizada, posto que não se pode retomar a situação vivenciada, que é única, irrepetível.

Isso posto, chega-se ao último estágio da leitura enunciativa empreitada neste estudo, que diz respeito aos instrumentos que possibilitam a realização do ato enunciativo. É valido retomar, como ponto de partida para esta fase da análise, que o enunciador é movido a produzir determinados enunciados por uma motivação/intenção discursiva, linguisticamente construída. Diante disso, pondera-se que, sendo a enunciação abstrata e fugaz, torna-se impossível apreendê-la em sua totalidade. A materialidade discursiva, por outro lado, carrega marcas enunciativas que desvelam a intenção comunicativo-interativa corporificada no engendramento textual, permitindo, em certa medida, que se acesse a própria enunciação.
Também, cumpre ressaltar que, dentre os diversos instrumentos possíveis de se articular no processo enunciativo, são os procedimentos acessórios, como vocabulário e arranjos sintagmáticos, que denunciam os efeitos de sentido pretendidos pelo enunciador, bem como projetam na materialidade textual a subjetividade e a semantização. Na primeira estrofe, por exemplo, a inscrição da locução adjetiva "de lenda", que determina o substantivo "país", permite inferir duas acepções semânticas: a) ao substituir a referida locução por um adjetivo equivalente, chegase ao vocábulo "lendário", que circunda um imaginário de grandeza, de feitos que ficam registrados na história e na memória para a posteridade, atribuindo, então, valor positivo ao referente; b) outro viés interpretativo permite inferir que a locução "de lenda" insere-se em um campo semântico que faz referência a fatos inverídicos, que são, portanto, constituintes de uma memória sociohistórica ficcional, ou seja, toda a grandeza conferida ao referido substantivo seria parte, unicamente, de uma lembrança desfocada e corrompida pelo distanciamento temporal entre o enunciador e o referente do discurso.

Essa mesma dúvida quanto à real existência e aos atributos conferidos ao país almejado pelo "eu" lírico/enunciativo se repete na terceira estrofe: "O meu País de sonho e de ansiedade, / Não sei se esta quimera que me assombra, / É feita de mentira ou de verdade". O enunciador qualifica, novamente, o vocábulo "país" por meio da inserção de duas locuções adjetivas - "de sonho" e "de ansiedade" -, sendo que os efeitos semânticos por elas produzidos conferem, novamente, incerteza quanto à imagem que a memória oferece em relação ao referente: as palavras "sonho", "ansiedade" e "quimera" reforçam a ideia de algo imaginado, uma vez que as duas primeiras apontam para uma possibilidade de futuro, algo não vivenciado, enquanto a última diz respeito a algo fantasioso, portanto, não real. Essa tênue e movediça distinção entre real e imaginário é reforçada 
pela projeção simultânea de duas locuções adjetivas com valores contrários, com vistas a atribuir características ao substantivo "quimera". Isto é, a inscrição das locuções "de mentira" ou "de verdade" em um mesmo patamar discursivo, revela a incerteza do "eu" lírico em qualificar suas memórias como constituintes de um espectro verdadeiro ou mentiroso, tangível ou meramente fantasioso.

Em contrapartida, o soneto em análise, considerando sua extensão, projeta uma considerável quantia de vocábulos que fundamentam a construção de uma imagem de grandeza, fartura e nobreza, como, por exemplo, "brocados", “joias”, “aias”, "Rainha Santa”, “opala”, “Reino”. Os referidos lexemas não só corroboram o engendramento de um imaginário de um período de riquezas e fartura, como, também, e principalmente, justificam o desejo de retorno manifestado pelo "eu" lírico na última estrofe do soneto Nostalgia - "Quero voltar!".

Nesse mesmo sentido, a interjeição "Ah!" corporifica um anseio que habita o interior do enunciador, sentimento este que é melhor delineado nos versos seguintes: "Não ser mais que a sombra duma sombra /Por entre tanta sombra igual a mim!". O emprego do vocábulo "sombra", repetido três vezes em apenas duas estrofes, enfatiza a concepção indenitária que o "eu" lírico tem de si mesmo, a qual é construída com alicerces em um sentimento nostálgico, que remonta ao esmagamento do presente quando contrastado às vivências idealizadas do passado e às possibilidades de um futuro virtualizado (JANKÉLÉVITCH, 1974). Em outras palavras, ao comparar a grandeza e o luxo que lhes pertenciam no passado às condições de sua vida presente, o "eu" lírico mostra-se decepcionado com o caráter ordinário de sua existência, comparando-se a uma sombra, portanto, sujeito comum ou, até mesmo, sem identidade.

Ressalta-se, por fim, que o corpus deste estudo, o soneto Nostalgia, constitui-se uma unidade complexa, estruturada por elementos linguísticos e pragmáticos, com vistas a materializar aspectos cognitivos e efetivar a interação entre interlocutores - um "eu" e um "tu" enunciativos. O referido material discursivo, então, manifesta-se em um tecido estruturado e uma entidade de comunicação, produzido em um determinado tempo e espaço, para uma finalidade discursiva específica, visando a (re)construir uma visão de mundo - calcada no desejo de retorno a um passado glorioso - e transmiti-la ao outro (o leitor ou ouvinte). Logo, enfatiza-se que nenhum texto é uma peça isolada ou uma mera manifestação da individualidade dos sujeitos, pois se constrói um texto para, por meio dele, posicionar-se frente à sociedade.

Diante da referida complexidade, comprovou-se, então, que a análise sistemática dos elementos constituintes do processo enunciativo - o ato, as situações e os instrumentos de sua realização - possibilita conferir um olhar mais atento e aprofundado ao material discursivo sobre o qual se debruça, posto que, a partir da análise de elementos pragmáticos, sintáticos e semânticos inscritos na superfície textual, viabiliza-se a inferência dos sentidos projetados na subjacência discursiva.

\section{Considerações finais}

A partir das discussões aqui desenvolvidas, ficou evidente que a interação humana é feita pela representação, sendo, na maioria das vezes, a partir de textos falados e/ou escritos, construídos pelo uso de signos linguísticos, que são uma forma de apreender a realidade, a qual só existe para os homens quando for nomeada. Nesse processo enunciativo, o enunciador se apropria virtualmente da língua e, normalmente, acaba por inscrever-se no discurso, deixando vestígios, marcas enunciativas do próprio dizer na materialidade discursiva, as quais devem ser reconhecidas e ressignificadas pelo leitor, pois projetam determinados efeitos de sentido no texto. 
Diante desse contexto, o estudo articulou-se em torno do complexo processo de ressignificação textual, buscando subsídios em pressupostos da Enunciação e da Literatura, com o objetivo de, ao delinear um percurso de leitura enunciativa, analisar marcas enunciativo-discursivas inscritas em um texto poético, as quais interferem na constituição semântica do texto. 0 cunho interdisciplinar inscrito no estudo, certamente, possibilitou depositar um olhar ao mesmo tempo mais amplo e mais profundo ao texto literário analisado, o qual requer um olhar mais atento e sistemático no processo de leitura, uma vez que confere um trato enriquecido aos recursos linguísticos manipulados na materialização discursiva.

Também, observou-se que a memória assume papel decisivo na construção do sentimento nostálgico inscrito no soneto analisado, bem como nas mais variadas formas de manifestação linguístico-discursivas. Isto é, pôde-se enfatizar que nossas experiências passadas não se inscrevem em um tempo isolado do presente, mas que, a todo momento, comunicam-se com este, interferindo, na maioria das vezes, até mesmo na construção de um universo sociodiscursivo contemporâneo. Logo, fica nítido ser do presente que se parte o apelo por uma retomada virtual de um passado idealizado, que é retextualizado a partir de lembranças de sujeitos ausentes de espírito do ambiente em que estão presentes na forma carnal, e, por algum motivo específico (insatisfação, decepção, sofrimento, saudade etc.), lamentam o distanciamento e a impossibilidade de retorno a momentos representados na memória como de glórias e/ou alegrias.

Ressalta-se, por fim, que o processo de ressignificação textual é complexo e desafiador, posto que envolve aspectos pragmáticos e cognitivos. Além disso, embora o ato de ler, assim como a interação com textos, seja intrínseco às relações sociocomunicativas, ninguém nasce leitor. A habilidade leitora, por esse viés, tanto não é privilégio de poucos indivíduos que tenham nascido com um dom específico para isso, como tampouco é alcançada unicamente por meio de inúmeras e cansativas leituras. Essa habilidade, portanto, deve ser desenvolvida, uma vez que a compreensão está associada à observação de traços projetados na materialidade textual e a conhecimentos específicos a serem mobilizados no processo de inferência - como se observou não só nas discussões teóricas aqui apresentadas, mas, principalmente, no processo analítico a elas articulado.

\section{Referências}

BENVENISTE, E. Da subjetividade na linguagem. In: BENVENISTE, E. Problemas de Linguística Geral I. São Paulo: Companhia Editora Nacional, Editora da Universidade de São Paulo, 1976a. p. 284-293.

BENVENISTE, E. Vista d'olhos sobre o desenvolvimento da linguística. In: BENVENISTE, E. Problemas de Linguística Geral I. São Paulo: Companhia Editora Nacional, Editora da Universidade de São Paulo, 1976b. p. 19-33

BENVENISTE, E. O aparelho formal da enunciação. In: BENVENISTE, E. Problemas de Linguística Geral II. São Paulo: Pontes, 2006a. p. 81-92.

BENVENISTE, E. A linguagem e a experiência humana. In: BENVENISTE, E. Problemas de Linguística geral II. São Paulo: Pontes, 2006b. 70-80

BENVENISTE, E. Semiologia da língua. In: BENVENISTE, E. Problemas de Linguística Geral II. São Paulo: Pontes, 2006c. p. 47-69.

JANKÉLÉVITCH, V. L'irreversible et la nostalgie. Paris: Flammarion, 1974.

SAUSSURE, Ferdinand de. Curso de linguística geral. São Paulo: Cultrix, 2006.

STAROBINSKI, Jean. Il concetto di nostalgia. In: PRETE, Antonio. Nostalgia. Storia di un sentimento. Disponível em: <https://pt.scribd.com/document/354166916/JeanStarobinski-A-tinta-da-melancolia-Uma-histA-ria-cultural-da-tristeza-Companhia-dasLetras-2016\#Search_search-menu_165761>. Acesso em: jan. 2018.

Recebido em 30/06/2018

Aceito em 25/09/2018 